Published in the European Journal of Criminology (submitted version)

Reference as:

Valente, R, Lanna, LC, and Chainey, SP (2018) Participatory design of a thematic questionnaire in the field of victimization studies. European Journal of Criminology. https://doi.org/10.1177/1477370818769597

\title{
Participatory design of a thematic questionnaire in the field of victimization studies
}

Riccardo Valente

University of Barcelona, Spain

Lucrezia Crescenzi Lanna

Universitat de Vic - Universitat Central de Catalunya, Spain

Spencer Chainey

University College London, UK

\begin{abstract}
The paper introduces the results of a two-step process that led to the design of a new questionnaire in the field of victimization studies. A desk-based review of national crime and victimization surveys from five EU countries was performed and resulted in
\end{abstract}


identifying opportunities to improve the consistency among these surveys as well as the need to include more independent variables in order to measure fear of crime and its correlation with sociological variables. Then, twelve experts in survey-based measures of crime-related issues were involved in a Delphi panel with the objective of enhancing a participatory design of a new questionnaire addressing individual and space-based determinants of the perception of insecurity that has been poorly explored to date.

\section{Keywords}

Crime and Victimization Surveys, Delphi method, fear of crime, perception of insecurity

\section{Introduction: survey-based measures of crime, victimization and perceived insecurity}

Survey-based measures of crime date back to the late 1960s and were developed in order to offer well-grounded knowledge that could complement administrative records and police statistics. The first survey-based measure was launched in 1965, when the former president of the United States Lyndon Johnson, responding to rising crime, decided to appoint a commission with the objective of examining the causes of criminality. At the time, the only measure of crime available to policymakers was from data on crime reported to and recorded by law enforcement agencies. Although, according to the 
conclusions of the President's Commission, 'police agencies are to some degree dipping deeper into the vast reservoir of unreported crime' (President's Commission on Law Enforcement and the Administration of Justice, 1967: 40), it was recognised that police recorded crime was not sufficient alone to determine an accurate assessment of the true extent of crime. In order to improve the assessment on the extent of crime, the Commission suggested the implementation of a self-report survey at the national level for collecting information on people's experiences of crime and characteristics associated with their victimisation. The proposed survey of crime and victimisation was considered to be a means of helping to improve the accuracy of the true measure of crime by capturing information that had not been reported to the police, and improve information that would help better understand the circumstances that related to victimisation.

The first National Crime Victimization Survey (NCVS) was carried out in the United States in 1973. By directly asking people about their experiences with crime and comparing this to the level of self-disclosed victimisation from police recorded crime statistics, the "dark figure" of crime was revealed (Boivin and Cordeau, 2011; Messner, 1984; Skogan, 1974) - the difference between the crimes that actually occur and those that are reported to the police. The survey also collected information relating to people's feelings of safety at home or in the neighbourhood in which they live, fear of being the victim of a crime, assessment of personal risk to being a victim of crime, worry about criminality in general, personal wellbeing, and opinions on the effectiveness of the police 
and the criminal justice system. The National Crime Victimization Survey has become an integral part of crime statistics in the U.S. and is carried out on an annual basis since its first edition.

Ever since the introduction of the NCVS in the U.S., survey-based measures of crime have become widely adopted in countries in the European Union (for a comprehensive review, see Aebi and Linde, 2010) and internationally as a way to complement police recorded crime data. Whilst western industrialised countries are considered to have led the way in developing and conducting national crime victimisation surveys (hereinafter referred to as CVSs), CVSs have also been implemented in African countries (Nigeria, Rwanda, Egypt, Kenya and South Africa) under the guidance of the United Nations Office on Drugs and Crime (UNODC), in Asia (for example, the International Public Safety Survey in Kyrgyzstan in 2015) and in Latin American and Caribbean countries through the VICLAC-LACSI initiative (United Nations Economic and Social Council, 2015). In turn, the adoption of national CVSs has led to attempts to compare results between surveys, with the work of Clinard (1978) being recognized as the first attempt to examine the viability of comparing CVSs. The International Crime Victim Survey (ICVS) stands out among other efforts to generate cross-national comparisons and to provide a framework for fully standardised surveys oriented toward the measurement of victimization experiences (Van Dijk, 2014; Van Dijk, Mayhew and Killias, 1990). 
As argued by Cantor and Lynch (2000: 86), CVSs 'substantially changed the definition of crime and the nature of the information available on crime events'. Whilst administrative crime statistics are based on the offences that are reported to or recorded by police agencies, CVSs collect personal information from individuals about their experiences with crime. As such, by its very nature, survey-based measures help to reveal different aspects relating to citizens' needs and expectations about their own safety, and can improve the understanding of the causes of insecurity. It has become commonly accepted that police recorded crime data by themselves are not sufficient to explain variations in terms of people's experiences and perceptions of crime due to the recognised extent to which crimes are not reported to the police and the influence that exposure to popular media has on the fear of crime (Cashmore, 2014; Greer, 2010), physical and social vulnerability (Killias and Clerici, 2000; Pantazis, 2000) and contextual factors related to ecological characteristics of places in which people live (Sampson and Raudenbush, 2004; Van Ham et al., 2012).

\section{Measuring fear of crime and the perception of insecurity: the case of five CVSs at the EU level}

According to Franklin and colleagues (2008), three models can be used for explaining the variations of fear of crime among citizens: the vulnerability model, the disorder model, and social integration model. The vulnerability model assumes that people's physical and 
social vulnerability are associated with the highest levels of insecurity (Jackson, 2009; Vieno, Roccato and Russo, 2013). Authors that have adopted the disorder model suggest there is a close link between the emergence of anti-social behaviours and the physical decay of neighbourhoods in which people live and their exposure to insecurity (Müller and Fischer, 2015; Sampson, 2012). The social integration model is used to explain fear of crime and perception of insecurity as a direct consequence of people's disaffiliation (Brunton-Smith and Jackson, 2012; Pinkster, 2014).

Recent theoretical developments have tried to adopt more focused approaches by pointing out the difference between two basic dimensions - the objective and the subjective. The objective dimension refers to the influence of actual crime rates on people's feeling of unsafety. The subjective dimension encompasses a continuum of emotional and cognitive factors affecting perceived insecurity. Assuming this difference, fear of crime is conceived as a particular declination of the broad concept of perceived insecurity. As a general definition it could be argued that fear of crime mainly refers to a negative mental state in reaction to victimization (i.e., being a victim of crime), while perception of insecurity is more related to cognitive perceived risk theories (Valera and Guàrdia, 2014). Furthermore, Solymosi and colleagues (2015) point out that fear of crime - and, by extension, perception of insecurity - is a dynamic phenomenon, being influenced by particular locations, times and activities, and which leads to recognising that a weakness of existing surveys is that they only capture static feelings of insecurity (Gray, Jackson 
and Farrall, 2008).

Bearing in mind current advances in the field of victimization studies, a desk-based analysis has been conducted within the framework of an on-going research project called MARGIN (Project MARGIN, 2017) with the purpose of comparing the way to measure fear of crime and the perception of insecurity through CVSs across five EU countries. Project MARGIN has involved partners in France, the United Kingdom, Spain, Italy and Hungary conducting collaborative research for developing strategies that help tackle insecurity in marginalised areas. The desk-based analysis of CVSs involved reviewing the content of five surveys: Cadre de vie et sécurité (France), Crime Survey for England and Wales (UK), Encuesta de Seguridad Pública de Cataluña (Spain), Sicurezza dei cittadini (Italy) and Victims and Opinion Research (Hungary). The analysis of these CVSs revealed three particular weaknesses that limited the opportunities for the survey results to be compared:

1. The lack of an agreed framework for operationalising the constructs of "fear of crime" and "perception of insecurity";

2. As a consequence of the above, the lack of consistency and comprehensiveness in the range of measures of the victimization experience(s);

3. The lack of independent variables containing information about the demographic and socio-economic characteristics of the surveys' respondents, which are 
necessary for measuring people's fear of crime and its relationship with sociological variables.

In relation to the first weakness identified, the analysis of the CVSs revealed that measures of fear of crime generally followed the tradition inaugurated by the U.S. National Crime Victimization Survey (NCVS). For example, the surveys include questions that ask people how safe they feel "walking alone" in their neighbourhood "after dark". This question has received extensive criticisms in the literature due to the fact that the exposure to the feeling of unsafety after dark depends on whether a person actually walks alone after dark or not. More precisely, authors such as Ferraro and LaGrange (1979), Holfreter and colleagues (2015) or Pratt and colleagues (2014) argue that the contemplation of activities such as leaving home and going out as pre-conditions for exposure to risky situations is highly controversial considering that leaving home may increase the possibility of falling victim to burglary or being the victim of another street crime (e.g. robbery), and may also reduce the risk to predominantly home-based crimes against the person, such as domestic violence (Pratt and Turanovic, 2015). Similarly, the act of going out per se is not immediately connected with victimization since what really matters is what individuals actually do outside. Across the five surveys analysed, only the Crime Survey for England and Wales (CSEW) has developed alternative measures in an attempt to overcome this limitation. This includes the introduction in 2003/2004 to the CSEW of a more direct assessment of the situational causes of the fear of crime by asking 
specifically about the situation when the respondent felt insecure by asking questions related to the frequency of the feeling of fear (e.g., How frequently have you felt [worried] in the last year?) and the intensity of the feeling (e.g., On the last occasion how fearful did you feel?).

The lack of consistency and comprehensiveness in the range of possible measures of victimisation experience associated with the five different CVSs illustrated how measures for exploring the actual experiences of personal victimization differed greatly between the five countries. For example, the Hungarian CVS asks questions concerning crime in a broad sense, as opposed to asking questions specifically about certain types of crime. This is quite different to the CSEW and the French and Italian CVSs where questions are asked that are specific to certain crime types. Furthermore, a feature of the Catalan survey is that respondents are asked to recall "spontaneous memories of victimization" (e.g., Do you recall whether at any time in the last year you were the victim of any offence?) with the objective of identifying the vivid recollection of one's personal experience, in an attempt to measure the impact of victimization on individuals. The lack of consistency in the content of the questions asked on victimisation experience in different national CVSs in turn makes it difficult for comparisons to be made between countries. The analysis of the five CVSs also revealed a general lack of detail relating to questions on victimisation experience, and the need (alongside better consistency) for questions relating to historical victimization experiences (both against the respondent and their family), information on 
the concentration of victimization, and repeated or chronic victimization. Other questions that might be considered include whether the risk of victimization is improving or declining, whether the fear of crime or feelings of insecurity actually influence the behaviour of the respondent (e.g., avoiding places at certain times of the day), and what changes, if any, an experience of victimization had on influencing the activities of victims (such as improving their home security after experiencing a burglary).

The third issue identified from the analysis of the five CVSs was the lack of independent variables addressing the demographic and socio-economic characteristics of the surveys' respondents. Each of the surveys that were analysed contained a large number of independent variables that could be used to analyse associations between individual characteristics and perceived insecurity but, only six of the same variables were recorded by each survey. These were gender, age, employment status, whether the respondent is a student, whether they were born outside the country in which the survey was conducted, and whether or not they had a degree. Even within some of these six variables, there exist cross-country differences in the way they are measured, which leads to difficulties when comparing findings across countries. For instance, definitions of unemployment vary across the five countries, depending on the type of employment which is being referred to (e.g., full time/part time), how long the respondent has been unemployed, and whether they are receiving any financial support from the government. Similar definitional issues also arose in the case of being born outside the country. In Italy, for instance, the national 
CVS includes a question concerning the citizenship of the respondent, whilst in Hungary the same variable is obtained by considering a question on the country of birth, since questions regarding citizenship are not available. In England and Wales, questions regarding both nationality and the country of birth of the respondent are asked. In terms of considering the causal effect of being born outside of the county on the subsequent level of perceived insecurity, there are other variables that are likely to be of equal importance and which in most cases were not included in the victimization surveys. For example, an important variable relating to examining victimization against immigrants and minority ethnic groups is the length of time the respondent has lived in the country, or whether their parents were also born outside the country. In some cultures, certain variables are considered to be too sensitive to collect (or, indeed, even illegal to collect), but which if collected can provide important insights into the victimization of crime. For example, the England and Wales CVS includes questions relating to a person's race and origins, which in France is illegal to ask.

Two of the five surveys (England and Wales, and France) also include a question relating to the health status of respondents. Given that the results of recent research outline the possible link between health-related concerns and fear of crime, and the potential for positive feedback between feelings of insecurity and mental and physical health (Jackson and Stafford, 2009; Lorenc et al., 2014), it would appear important to capture information relating to the health of respondents in crime victimization surveys. While there are 
practical considerations involved in collating information on health (such as definitional and sensitivity issues posing problems for objective measures of health) it would be valuable to capture information on health in a standard manner in CVSs to allow each survey to benefit from the results this would offer and to support cross-national comparisons.

\section{Objectives}

The objective of the research was to design a new thematic questionnaire on the victimization of crime with a view towards overcoming the limitations that had been identified from previous CVSs, and in particular from our experiences in the limitations in comparing between CVSs from five different countries - Spain, England and Wales, France, Italy and Hungary. In recognition of the need to consider contextual factors when analysing victimization, fear of crime and the perception of insecurity, the current research pursues the suggestion of Killias (2010) to collect more and better independent variables in order to improve our understanding of why people's perception of insecurity increases or decreases. Through the determination and inclusion of a better consistent set of explanatory variables that may help to understand differences, trends and variations of perceived insecurity, this in turn would improve the value of each CVS.

In this paper we introduce a new thematic crime victimisation questionnaire, designed with the specific objective of operationalizing a core group of indicators that allow for 
analysing whether individual factors (gender, age, nationality, income, lifestyle and the degree of social inclusion) and situational factors (socio-economic features of neighbourhoods, urban layout and the degree of social cohesion) might influence perceptions of insecurity. Our primary focus is on urban areas with over 50,000 inhabitants (due in part to the resources available for conducting the questionnaire in the five countries of the Project MARGIN participants, and the greater level of insecurity that is typically felt in urban rather than rural areas). The objective, therefore, was not to simply replicate the contents of existing CVSs but to provide insights on aspects that have previously been poorly addressed. Under this objective, the proposed questionnaire aims to improve the use of demographic and socio-geographic determinants of the perception of insecurity rather than extending the study of victimization in itself. To achieve this, the research adopted a Delphi method process to foster a participatory questionnaire design involving representatives from the five countries participating in Project MARGIN.

\section{Method}

The research involved the first known attempt to use the Delphi method to design questionnaires for constructing Crime and Victimization Surveys.

The Delphi method is a research technique first piloted in the framework of the so-called “Delphi project" launched by the RAND Corporation in the United States (Dalkey, 1969). Since the 1970s, the Delphi method has been widely used for converging opinions among 
experts within certain topic areas (for a comprehensive review of the use of the Delphi technique across different disciplines, see: Linstone and Turoff, 2002). The implementation of the Delphi method consists of a communication process structured around a series of questionnaires to collect data from a panel of selected experts. After each data collection stage, the Delphi coordinator (Levine and Hogg, 2010) provides an anonymous summary of the experts' opinions. The feedback process encourages the panellists to reconsider their initial opinions, generate additional insights and clarify the information developed within the previous round. Then, the results arising from previous iterations provide inputs on specific items that can be amended by the panellists in later iterations. As such, over the course of multiple iterations the experts are expected to become more problem-solving oriented.

The Delphi method implemented for the purposes of the current research was intended to reach consensus among twelve international experts in the field of victimization studies. The use of twelve experts fitted in line with the recommendation of Delbecq and colleagues (1975) on the adequate number of participants to involve in the process (between ten and fifteen panellists are recommended). Experts were heterogeneous with regard to age, background and current working position. The participants were chosen to represent different fields of expertise (criminology, victimology, sociology, social psychology, and crime statistics) in order to ensure a multidisciplinary approach to the questionnaire's design. The panel's composition was also intentionally multi-stakeholder 
and the experts' institutional affiliation varied from academia and research institutes to public institutions dealing with security issues. Gender balance within the panel was duly taken into account, as shown in Table 1. The MARGIN project's management structure also relied on the participation of an "Ethics Advisory Board" that was responsible for supervising and solving potential ethics issues throughout the implementation of the Delphi method. Further independent scrutiny of the Delphi method and the final version of the questionnaire was provided by project evaluators from the European Commission and by external experts from each of the five countries represented in the MARGIN project.

$<$ Table 1 about here. Main characteristics of the panel of experts involved in the Delphi procedure>

The Delphi process was structured into four rounds (three online rounds plus a final round in situ). This Delphi process characterizes the methodological approach as a "modified Delphi method" (Custer, Scarcella, and Stewart, 1999), particularly prominent in health research (Escaron et al., 2016; Eubank et al., 2016), by combining technology-mediated inputs with face-to-face consensus building (see Figure 1).

<Figure 1 about here. Structure of the Delphi process used to design the questionnaire> 
The modified Delphi method involved both quantitative and qualitative data. While the Delphi method has been typically used as a quantitative technique (Rowe and Wright, 1999), the review of the literature shows that its implementation has been flexible, especially when the purpose of the research involves interpreting a broad social phenomenon from a holistic perspective (Creswell, 1998). Completion of the four rounds of the modified Delphi method took a total of 44 working days, from 19 February to 14 June 2016. The amount of time for the administration of the four rounds was compatible with the recommendations of Delbecq and colleagues (1975).

Implementation of the Delphi method and analysis of the inputs from the panellists During the first three rounds of the Delphi method (which were performed online), the experts were asked to numerically rate on a Likert-type scale, ranging from 1 (poor rating) to 5 (best rating), the relevance (i.e., whether the proposed items fitted with the purpose of the research objective) and the wording (i.e., meaningfulness of the questions and the related answers categories) of the items proposed by the Delphi coordinator. The rating exercise was intended to establish preliminary priorities among the experts. A comments box was available below each item to gather the experts' personal and more detailed insights. Digitized versions of the questionnaires were created at the beginning of each round by using the web-based form builder JotForm (http://www.jotform.com). 
During round 1 (19-25 February 2016), the panellists assigned numerical values from 1 to 5 in order to assess the relevance and the wording of 394 items (consisting of 31 unique questions and 363 answer categories) proposed on the basis of the conclusions drawn from the analysis of the five CVSs that had been previously reviewed. The objective was to reach an agreement on how to operationalize the indicators relating to the demographic and socio-economic status of the respondents, their fear of crime, perceived insecurity, direct victimization and perception of the risk of being victimized. The panellists' comments were used to rewrite those items that, despite receiving high ratings in terms of relevance, needed improved wording. During round 2 (11-17 March 2016), 385 newly formulated items (consisting of 33 questions and 352 answer categories) were reintroduced corresponding to those items that were poorly addressed by the experts in the previous round. Moreover, based on the suggestion of one expert, the questionnaire used in round 2 included topics relating to cyber-victimization. In the framework of round 3 (8-14 April 2016), the experts were required to express their ratings on 11 items (consisting of 6 questions and 5 answer categories) relating to two topics that had remained unsolved from the previous rounds (i.e., where an adequate rating had not been reached). The objective was to reach agreement on how to address both direct and indirect victimization in a way that was not time-consuming (i.e., as few items as possible) as well as to include some questions allowing to contrast the respondents' lifestyles with their levels of perceived insecurity. Finally, the experts were also asked to establish the order 
and the sequence of the different questions included in a provisional draft of the questionnaire.

After each one of the three rounds performed online, the Delphi coordinator was responsible for carrying out the correspondent analysis and preparing feedback on the results, the reasons for extreme positions and a call for reassessment (second and third rounds). The analysis of data gathered throughout the first three rounds focused on the numerical rating assigned by the experts to each question/answer category, with the objective of delineating areas of agreement/disagreement around the items proposed by the Delphi coordinator. Establishing a sound measure of consensus is a very sensitive issue for research using the Delphi method (for a comprehensive review, see Von der Gracht, 2012). In this case, after measuring the experts' average ratings for each question and answer category both for the measures of relevance and wording, the standard deviation of each rating was calculated. Standard deviation was then used as a measure of the degree of agreement/disagreement among the panellists. The criterion for consensus was satisfied when the average rating for each item was 4 or higher and the standard deviation was below 1 . Such a procedure for consensus measurement is endorsed by previous research (Doke and Swanson, 1995; Rogers and Lopez, 2002; West and Cannon, 1988). Finally, in order to guide the experts through the review of the results, a classification into quartiles was created by dividing the items into four groups: (A) very well rated, (B) mostly well rated, (C) mostly poorly rated and (D) very poorly rated. This 
analysis was performed by the Delphi coordinator the week following each round and involved preparing feedback to the panellists of a structured summary of the results, including measures of central tendency and dispersion (interquartile range and standard deviation).

Over the first three rounds it was impossible to reach a consensus on two topics: how to fully address the relationship between people's lifestyle(s) and their perception of insecurity; and whether or not specific items on fear of being victimized and perceived disorder should have been included in the questionnaire. Face-to-face panel interaction is considered particularly suitable when it is difficult to reach a consensus online, as this helps to better exchange views and to resolve uncertainties (Boulkedid et al., 2011). In the case of this research, the final round took place during a dedicated meeting hosted by the Spanish representatives of Project MARGIN in Barcelona (13 June 2016), and provided the advantage of facilitating a more comprehensive debate on the topics that had remained unsolved. At the beginning of the meeting each panellist received a document showing the results from previous rounds. The Delphi coordinator recalled the main conclusions from previous rounds and asked the panellists to briefly introduce their arguments in favour or against each one of the unresolved topics. Once the discussion on a given topic had concluded, the moderator noted the questions with the exact wording that appeared to generate consensus among the experts. Consensus was considered to have been reached when at least $75 \%$ of the panellists (i.e., 9 out of 12 experts) expressed 
explicit verbal agreement. Verbal agreement as a measure of consensus is grounded in previous research (García de Leonardo et al., 2016). In light of the results obtained throughout the Delphi process, the final version of the questionnaire was designed.

\section{Results: a new thematic questionnaire in the field of victimization studies}

The structure of the questionnaire, denoted as the "MARGIN Questionnaire on Perception of Insecurity" (2016), consists of 29 questions covering five analytical dimensions or constructs relating to crime and the perception of insecurity: objective insecurity, subjective perception, social insecurity, socio-geographic dimension, and lifestyle ${ }^{1}$.

\section{Objective insecurity}

This construct refers to people's experiences with victimization. In the case of the MARGIN questionnaire, a unique question was included that addresses both direct and indirect victimization: During the last 12 months, have you or someone close to you been the victim of crime? If a person had been the victim of multiple types of crime, the respondent is asked to recall only the "most recent" episode s/he was a victim, and then, specify "how many times it [the most recent crime] had [previously] happened", "where

\footnotetext{
${ }^{1}$ The order of questions and their distribution across the different modules of the questionnaire was a matter of discussion within the Delphi method's panel. Whilst from a research point of view we were purposeful in our approach to allow a separate examination of each of the five analytical dimensions, the sequence of questions in the questionnaire broadly followed this same structure but in places overlapped with other dimensions to ensure an appropriate flow to the questions that were asked.
} 
it took place" and "what s/he was doing at the time it happened". No follow-up questions are asked for indirect victimization. Two typologies of crime are addressed in the victimization module of the questionnaire: crimes against property (i.e., burglary dwelling, thefts of personal objects and vehicle-related thefts), and violent/contact crimes (i.e., robberies, threats, assaults and sexual assaults). A further question examined whether the experience of victimization resulted in the victimized person to change his/her behaviour or to take self-protective measures to avoid new victimization episodes: As a result of what happened, what actions, if any, did you or your household take in order to try to prevent it from happening again?

\section{Subjective perception}

The subjective dimension of insecurity addressed by the MARGIN questionnaire covered the emotional, cognitive and behavioural reactions that people have in relation to several dimensions of insecurity. Specifically these referred to the perception of crime reality (e.g., How much crime do you think there is in your neighbourhood compared to 12 months ago?), expectations about the future (e.g., How do you believe security will evolve in your neighbourhood over the next 12 months?), assessment of police work (e.g., How confident are you that the police are effective at preventing crime?), and feelings of safety (e.g., How safe do you feel walking alone in your neighbourhood after dark?). In order to fully address feelings of safety, the questionnaire also asked for the amount of time spent "walking alone in your neighbourhood after dark" as well as the intensity of feeling 
of unsafety - How often do you feel unsafe in your neighbourhood? - on a scale ranging from 1 (never) to 10 (very often). A further item addressed the worry about being victimized - How worried are you about being the victim of a crime? - with its inclusion intending to establish a clear distinction between public fear (of something that may affect the neighbourhood as a whole) and personal/private fear (being personally concerned about crime).

\section{Social insecurity}

The construct of social insecurity takes up the conclusions of previous research that has shown the relationship between the social status of respondents and their perception of insecurity (Gray, Jackson and Farrall, 2011; Nilsson and Estrada, 2006; Staubi, Killias and Frey 2013; Vauclair and Bratanova, 2016; Vieno, Roccato and Russo, 2013). The MARGIN questionnaire was used to examine the hypothetical profile of socially insecure subjects, in terms of:

- Socio-economic status:

- Low educational attainment (no qualification);

○ Unemployed or precarious employment;

- Low income (below the monetary poverty threshold);

- Self-perception of ontological insecurity and anxiety-provoking situations:

- Perception of poor state of health and pessimism about the future; 
- Perception of poor financial situation and pessimism about the future;

- Perception of being socially excluded and/or marginalized:

- Because of labour situation;

- Because of religion;

- Because of ethnic background;

- Because of sexual orientation.

Together with factors of social insecurity, a demographic vulnerability hypothesis was also explored by including indicators that helped to ensure a gender-balanced sample and by recording the age of the respondents, bearing in mind that previous research showed that being female and elderly is positively related to feelings of insecurity, even though the understanding of what stimulates fear of crime among these groups has been limited (Franklin, Franklin and Fearn, 2008).

\section{Socio-geographic dimension}

The socio-geographic dimension, also known as "neighbourhood effects" (Sampson, 2012; Van Ham et al., 2012) provided a focus towards the following: (1) physical and/or social characteristics of spaces that could have a negative impact on the perception of residents and drive them to adopt a restricted range of behaviours; (2) self-perception regarding the degree of social capital between neighbours, and (3) sense of belonging. In our understanding, the focus on the neighbourhood as the unit of analysis is crucial in 
order to capture individuals' different ideas of what constitutes their neighbourhood and, accordingly, how they feel in places that they are more and less familiar with.

A topic associated with the socio-geographic dimension refers to the impact of anti-social behaviours on perceptions of insecurity. During the discussion held between the participants involved in the Delphi process, concerns were expressed about the cultural differences between countries on the meaning of anti-social behaviours and, accordingly, what behaviours deserve to be included within the category of "anti-social". In some countries, public intervention regulating anti-social behaviours falls under specific legislation (for instance, the Anti-Social Behaviour, Crime and Policing Act 2014 in the UK or the Ordenanza del Civismo in Catalonia). In other countries, such as in Italy, antisocial behaviours often overlap with concerns about physical degradation of public spaces under what is termed as degrado (decay). To overcome these limitations, the question agreed among the panellists (How worried are you about anti-social behaviours in your neighbourhood?) was accompanied by a short list of examples defining what this concept actually means (people hanging around making noise, being drunk, littering in public spaces) so that the responses and their interpretation would be consistent between the five countries in which the questionnaires were to be conducted.

\section{Lifestyle}


This fifth dimension could be considered as a cross-cutting dimension interrelated with the previous ones. The lifestyle dimension refers to two aspects: what behaviours cause insecurity among citizens, and what consequences does the feeling of insecurity generate in terms of behaviours. In other words, depending on the focus adopted, it would be suitable to ask the extent a given behaviour performed by others in public spaces may increase respondents' perceptions of insecurity or whether respondents modify their behaviour in accordance with the circumstances to avoid uncomfortable situations that make them feel unsafe. As such, in order to fully address the relationship between lifestyle and the perception of insecurity, the panellists agreed that the questionnaire should include the following:

- The respondents' degree of familiarity with the social environment;

- How much respondents feel like they belong in the neighbourhood;

- Whether they spend more time within or outside the neighbourhood;

- Whether or not perceived insecurity affects people's behaviours.

Consensus was reached within the Delphi panel on the following questions: the first being a means of measuring familiarity with the neighbourhood - How many years have you been living in your present neighbourhood?; and others relating to the degree of satisfaction of living in the neighbourhood, the resident's familiarity with their 
neighbours, and the feeling of being able to rely on their neighbours in case of need (each assessed on a scale ranging from 1 - totally agree - to 10 - totally disagree).

A further question was included in order to identify a profile of respondents based on a rough estimate of the time spent within and outside the neighbourhood: How much time do you spend outside your neighbourhood in a typical week? Despite the evident limitations of this question (i.e., the impossibility of knowing what kind of activities the respondent performs within or outside the neighbourhood), at the very least it permits the identification of respondents that spend the majority of their time within the neighbourhood (more exposed to the problems affecting the neighbourhood) versus those who do not (less exposed). Agreement was also reached on a final question that allowed for an examination of the potential consequences of perceived insecurity on daily and routine activities. This question made it possible to determine the level of avoidance behaviours that were motivated by fear and feelings of insecurity: How often do you change your plans and/or routine to avoid situations that make you feel unsafe?

\section{Conclusions}

Multidisciplinary and multi-stakeholders panels of experts seem to be a way to enrich current practices in designing survey-based measurement of perceptions of insecurity. The strength of the modified Delphi method process implemented in the framework of the current research lies in two aspects that were particularly relevant for ensuring the 
success of the whole process. Firstly, the preliminary analysis of the five CVSs provided the panel of experts with a vast amount of structured information, and was crucial to reduce potential conflict throughout the whole process. Secondly, the fact that the experts were also full members of the much broader research project within which the Delphi method was implemented increased their commitment and their willingness to cooperate.

The main constraint experienced in the development and use of the MARGIN questionnaire was the limit in the number of questions that can be asked to respondents. This required the panel of experts to distil different measures and factors associated with insecurity into as few questions as possible. For example, there was a desire from members of the panel to include greater structure and depth on questions relating to the victimisation experience or to address the relationship between activities performed outside the neighbourhood, travelling from and to the neighbourhood (including victimisation experience on public transport and how the use of public transport influences perceptions of crime), but this would have come at the expense of there being too many questions in the survey. What was decided instead was a questionnaire that was designed to examine victimisation and the factors that may explain variation in the perception of insecurity in a manner that is missed by many CVSs. Additionally, the lack of some questions relating to the topic of cyber-victimization in most CVSs, at a time when cybercrime is increasing (European Commission, 2012), is a matter the panel also discussed. Despite the general consensus among the experts on the panel on the relevance 
of cyber-victimization in contemporary societies, the majority had reservations for its inclusion in the questionnaire due to the need to include multiple additional questions on how people use the Internet before capturing information on experiences of cybervictimization. It was decided that the inclusion of questions on cyber-victimisation were beyond the scope of the current research, but that it is an important area of research that is required in the future.

The inputs provided by this research do not seek to operate on the presumption of replacing existing Crime and Victimisation Surveys but instead seek to provide new insights into relatively underexplored topics, such as the influence of socio-economic and socio-geographic factors on perceptions and the impact that the fear of crime and feelings of insecurity have on peoples' lives. The MARGIN Questionnaire on Perception of Insecurity (2016) has since been translated from English into five languages (Catalan, French, Hungarian, Italian and Spanish) and at the time of writing is being used in a largescale survey involving a sample of over 15,000 people in Italy by using the CATI system (Computer-Assisted Telephone Interviewing), with some integrations with the CAWI (Computer Assisted Web Interviewing) and CAMI (Computer Assisted Mobile interviews) methodologies. Italy was chosen from the five participating countries in Project MARGIN as the location for trialling the MARGIN Questionnaire on Perception of Insecurity to help encourage the improved use of victimization surveys in this country (each of the other four countries has more developed CVSs). The MARGIN 
Questionnaire on Perception of Insecurity will also be used in a small selection of neighbourhoods in four of the main cities ( $\mathrm{n}=100$ in each city) in each of the respective Project MARGIN participants' countries - Barcelona, Budapest, London and Paris. This trialling of the survey in five countries also helps to test the vocabulary of six different languages $^{2}$ to ensure questions are asked as intended to ensure comparability in the responses that are given. The results of the survey will valuably help determine the robustness and validity of the MARGIN Questionnaire on Perception of Insecurity, and help identify the causal factors that influence the variation in the perception of insecurity in contemporary urban societies.

\footnotetext{
${ }^{2}$ Spanish, Catalan, English, French, Italian and Hungarian.
} 


\section{References}

Aebi MF and Linde A (2010) Las encuestas de victimización en Europa: evolución histórica y situación actual. Revista de derecho penal y criminología 3(3): 211-298.

Boivin R and Cordeau G (2011) Measuring the Impact of Police Discretion on Official Crime Statistics: A Research Note. Police Quarterly 14(2): 186-203.

Boulkedid R et al. (2011) Using and Reporting the Delphi Method for Selecting Healthcare Quality Indicators: A Systematic Review. PLoS ONE 6(6): 1-9.

Brunton-Smith I and Jackson J (2012) Urban Fear and its Roots in Place. In: Ceccato V (eds) Urban Fabric of Crime and Fear, New York: Springer, pp. 55-82.

Cantor D and Lynch JP (2000) Self-Report Surveys as measures of Crime and Criminal Victimization. In: Duffee D (eds) Measurement and Analysis of Crime and Justice. Washington D.C.: US Department of Justice, pp. 85-138.

Cashmore J (2014) The 'Fear of Crime-Media Feedback' Cycle. Internet Journal of Criminology. Available at: http://www.internetjournalofcriminology.com/Cashmore_The_Fear_of_CrimeMedia_Feedback_Cycle_IJC_Jan_2014.pdf (accessed 20 January 2017).

Clinard M (1978) Comparative Crime Victimization Surveys - Some problems and results. International Journal of Criminology and Penology 6(3): 221-231.

Creswell JW (1998) Qualitative inquiry and research design: choosing among five traditions. London: Sage.

Custer RL, Scarcella JA and Stewart BR (1999). The modified Delphi technique: A rotational modification. Journal of Vocational and Technical Education 15(2): 1-10. 
Dalkey NC (1969) An experimental study of group opinion. Futures 1(5): 408-426.

Delbecq AL, Van de Ven AH and Gustafson DH (1975) Group techniques for program planning. Glenview, IL: Scott, Foresman, and Co.

Doke ER and Swanson NE (1995) Decision variables for selecting prototyping ininformation systems development: a Delphi study of MIS managers. Journal Information and Management 29: 173-182. is iscep?

Escaron AL et al. (2016) Testing an Adapted Modified Delphi Method. Synthesizing Multiple Stakeholder Ratings of Health Care Service Effectiveness. Health Promotion Practice 17(2): 217-225.

Eubank BH et al. (2016) Using the modified Delphi method to establish clinical consensus for the diagnosis and treatment of patients with rotator cuff pathology. BMC Medical Research Methodology 16(1): 56. DOI: 10.1186/s12874-016-0165-8.

European Commission (2012) Special Eurobarometer 390: Cyber Security. Brussels: European Commission. Available at: http://ec.europa.eu/public_opinion/archives/ebs/ebs_390_en.pdf (accessed 20 January 2017).

Ferraro KF and LaGrange RL (1987) The measurement of fear of crime. Sociological Inquiry 57(1): 70-101.

Franklin TW, Franklin CA and Fearn NE (2008). A Multilevel Analysis of the. Vulnerability, Disorder, and Social Integration Models of Fear of Crime. Social Justice Research 21: 204-227. 
García de Leonardo et al. (2016) A Latin American, Portuguese and Spanish consensus on a core communication curriculum for undergraduate medical education. BMC Medical Education 16: 99.

Gray E, Jackson J and Farrall S (2008) Reassessing the fear of crime. European Journal of Criminology, 5(3): 363-380.

Gray E, Jackson $\mathbf{J}$ and Farrall S (2011). Feeling and functions in the fear of crime. Applying a New Approach to Victimisation Insecurity. British Journal of Criminology 51: 75-94.

Greer C (2010) News Media Criminology. In: McLaughlin E and Newburn T (eds) The SAGE Handbook of Criminological Theory. Sage Publications: London, pp. 490-513.

Holtfreter K et al. (2015) Risky remote purchasing and identity theft victimization among older Internet users. Psychology, Crime \& Law 21: 681-698.

Jackson J (2009) A psychological perspective on vulnerability in the fear of crime. Psychology and Crime 15(4): 1-25.

Jackson J and Stafford M (2009) Public Health and Fear of Crime: A Prospective Cohort Study. British Journal of Criminology 49(6): 832-847.

Killias M (2010) Crime Surveys as Tools of Policy-making. In: Government of Catalonia, Ministry of Home Affairs, 10 Years of the Crime Victimisation Survey in Catalonia. European Experiences. Assessment and Future Challenges. Barcelona: Generalitat de Catalunya, pp. 9-18.

Killias M and Clerici C (2000) Different measures of vulnerability in their relation to different dimensions of fear of crime. The British Journal of Criminology 40: 437-450. 
Levine JM and Hogg MA (eds) (2010) Encyclopedia of group processes and intergroup relations, Thousand Oaks, CA: Sage.

Linstone H and Turoff M (2002) The Delphi Method: Techniques and Applications. London: Addison-Wesley.

Lorenc T et al. (2014) Crime, fear of crime and mental health: synthesis of theory and systematic reviews of interventions and qualitative evidence. Public Health Res 2(2): 124.

MARGIN Questionnaire on Perception of Insecurity (2016). Available at: https://www.researchgate.net/publication/309430359_MARGIN_Questionnaire_on_Per ception_of_Insecurity (accessed 20 January 2017). DOI: 10.13140/RG.2.2.27235.14886

Messner S (1984) The "dark figure" and composite indexes of crime: Some empirical explorations of alternative data sources. Journal of Criminal Justice 12(5): 435-444.

Müller T and Fischer T (2015) Feeling unsafe in a multicultural neighbourhood: indigenous inhabitnats' perspectives. British Journal of Criminology 55: 790-810.

Nilsson A and Estrada F (2006) The Inequality of Victimization. Trends in Exposure to Crime among Rich and Poor. European Journal of Criminology 3(4): 387-412.

Pantazis C (2000) "Fear of crime", vulnerability and poverty: Evidence from the British Crime Survey. British Journal of Criminology 40: 414-436.

Pinkster FM (2014) 'I Just Live Here’: Everyday Practices of Disaffiliation of Middleclass Households in Disadvantaged Neighbourhoods. Urban Studies 51(4): 810-826. 
Pratt TC and Turanovic JJ (2015) Lifestyle and Routine Activity Theories Revisited: The Importance of "Risk" to the Study of Victimization. Victims \& Offenders 00: 1-20.

Pratt TC et al. (2014) Self-control and victimization: A meta-analysis. Criminology 52: $87-116$.

President's Commission on Law Enforcement and the Administration of Justice (1967) Task force report: Crime and its impact. An assessment. Washington: U.S. Government $\begin{array}{lll}\text { Printing } & \text { Office. } & \text { Available }\end{array}$ https://www.ncjrs.gov/pdffiles1/Digitization/146852NCJRS.pdf (accessed 20 January 2017).

Project MARGIN (2017) Tackle insecurity in marginalised areas. Project ID: 653004. Funded under Horizon 2020 programme - Secure societies: Protecting freedom and security of Europe and its citizens. Available at: http://marginproject.eu/ (accessed 12 January 2017).

Rogers MR and Lopez EC (2002) Identifying critical cross-cultural school psychology

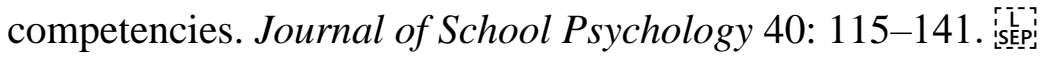

Rowe G and Wright G (1999) The Delphi technique as a forecasting tool: issues and analysis. International Journal of Forecasting 15: 353-375.

Sampson R (2012) Great American City. Chicago and the enduring neighbourhood effect. Chicago and London: The University of Chicago Press.istepi

Sampson R and Raudenbush S (2004) Seeing Disorder: Neighborhood Stigma and the Social Construction of "Broken Windows". Social Psychology Quarterly, 67(4): 319342. 
Skogan W (1974) The Validity of Official Crime Statistics: An Empirical Investigation. Social Science Quarterly 55(1): 25-39.

Solymosi R, Bowers K and Fujiyama T (2015) Mapping fear of crime as a contextdependent everyday experience that varies in space and time. Legal and Criminological Psychology 20: 193-211.

Staubi S, Killias M and Frey B (2013) Happiness and victimization: An empirical study for Switzerland. European Journal of Criminology 10(5): 515-533.

United Nations Economic and Social Council (2015) Report of the National Institute of Statistics and Geography of Mexico and the United Nations Office on Drugs and Crime on crime statistics. Available at: http://unstats.un.org/unsd/statcom/doc15/2015-8CrimeStats.pdf (accessed 20 January 2017).

Valera S and Guàrdia J (2014) Perceived insecurity and fear of crime in a city with lowcrime rates. Journal of Environmental Psychology 38: 195-205.

Van Dijk JJM (2014) The case for survey-based comparative measures of crime. European Journal of Criminology 12(4): 437-456.

Van Dijk JJM, Mayhew P and Killias M (1990) Experiences of Crime across the World. Key findings from the 1989 International Crime Survey. Deventer: Kluwer Law and Taxation Publishers.

Van Ham M et al. (eds) (2012) Neighbourhood Effects Research: New Perspectives. UK: Springer. 
Vauclair CM and Bratanova B (2016) Income inequality and fear of crime across the European region. European Journal of Criminology 1-21. DOI: $10.1177 / 1477370816648993$

Vieno A, Roccato M and Russo S (2013) Is Fear of Crime Mainly Social and Economic Insecurity in Disguise? A Multilevel Multinational Analysis. Journal of Community \& Applied Social Psychology 23: 519-535.

Von der Gracht HA (2012) Consensus measurement in Delphi studiesisepireview and implications for future quality assurance. Technological Forecasting \& Social Change 79: $1525-1536$.

West JF and Cannon GS (1998) Essential collaborative consultation competencies for regular and special educators. Journal of Learning Disabilities 21: 56. 
Table 1. Main characteristics of the panel of experts involved in the Delphi procedure

\begin{tabular}{|c|c|}
\hline CHARACTERISTICS & $\mathrm{n}$ \\
\hline \multicolumn{2}{|l|}{ Sex } \\
\hline Male & 6 \\
\hline Female & 6 \\
\hline \multicolumn{2}{|l|}{ Present professional setting } \\
\hline Academia & 5 \\
\hline Public institution in the field of security & 3 \\
\hline Public establishment of administration & 3 \\
\hline SME/private think tank & 1 \\
\hline \multicolumn{2}{|l|}{ Institutional affiliation } \\
\hline Dpt. Interior of Catalonia & 3 \\
\hline University of Milano-Bicocca & 2 \\
\hline University College London & 2 \\
\hline French National Institute for Advanced Studies in Security and Justice & 2 \\
\hline EuroCrime SrL & 1 \\
\hline Hungarian National Institute of Criminology & 1 \\
\hline University of Barcelona & 1 \\
\hline \multicolumn{2}{|l|}{ Geographical origin } \\
\hline Spain & 4 \\
\hline Italy & 3 \\
\hline UK & 2 \\
\hline France & 2 \\
\hline Hungary & 1 \\
\hline \multicolumn{2}{|l|}{ Field of expertise } \\
\hline Criminology & 4 \\
\hline Victimology & 2 \\
\hline Crime statistics & 3 \\
\hline Sociology & 2 \\
\hline Social psychology & 1 \\
\hline
\end{tabular}

Figure 1. Structure of the Delphi process used to design a new questionnaire in the field of victimization studies 


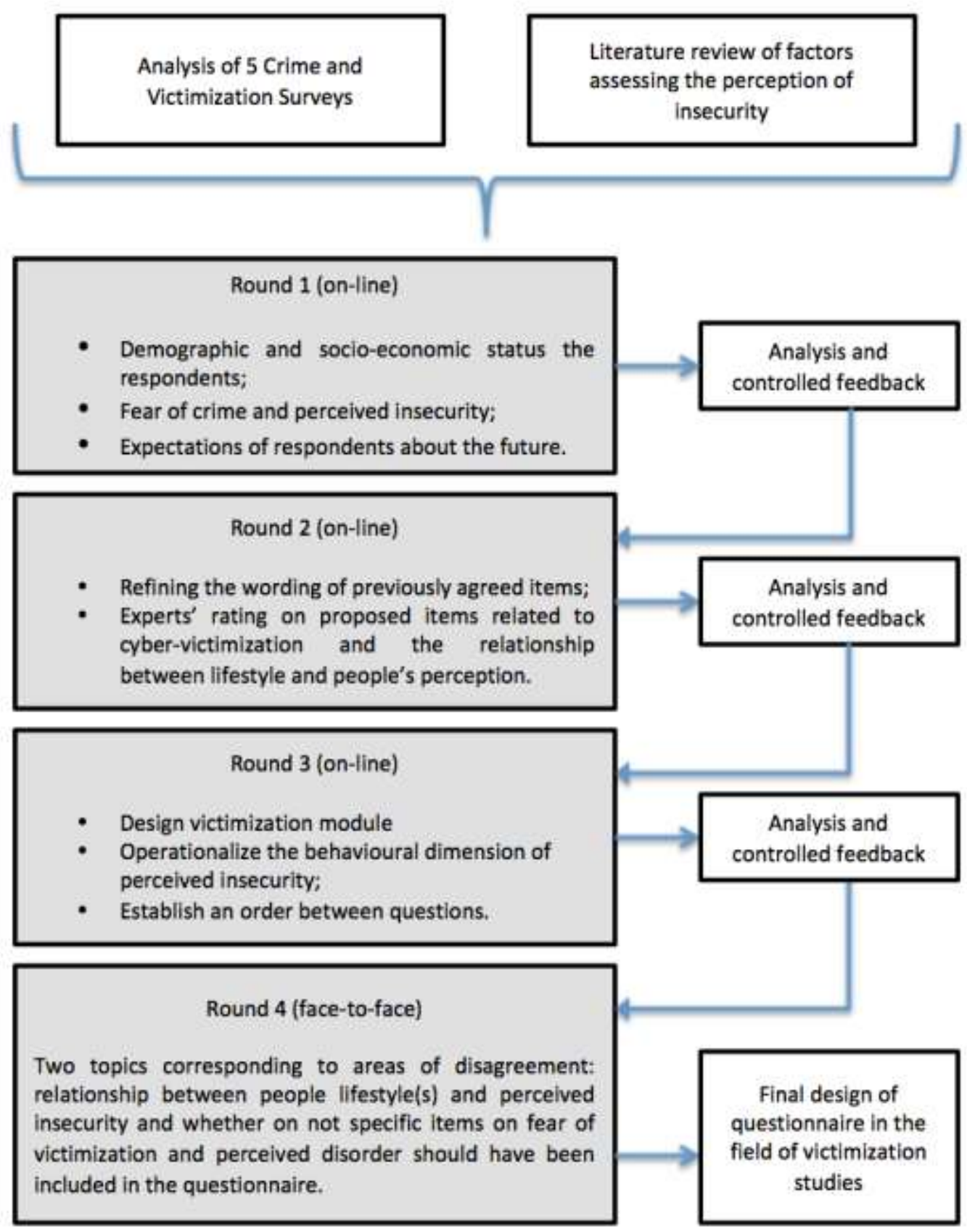

